\title{
Appearance of Klebsiella Pneumoniae Liver Abscess Syndrome in Argentina: Case Report and Review of Molecular Mechanisms of Pathogenesis
}

\author{
Andrea Vila ${ }^{1, *}$, Andrea Cassata ${ }^{1}$, Hugo Pagella ${ }^{1}$, Claudio Amadio ${ }^{2}$, Kuo-Ming Yeh $^{3}$, \\ Feng-Yee $\mathrm{Chang}^{3}$ and L. Kristopher $\mathrm{Siu}^{4}$
}

\author{
${ }^{1}$ Department of Infectious Diseases, Hospital Italiano de Mendoza, Avenida Acceso Este 1070, Guaymallén, Mendoza, \\ Argentina \\ ${ }^{2}$ Department of Internal Medicine, Hospital Italiano de Mendoza, Avenida Acceso Este 1070, Guaymallén, Mendoza, \\ Argentina \\ ${ }^{3}$ Division of Infectious Diseases and Tropical Medicine, Department of Internal Medicine, Tri-Service General \\ Hospital, National Defense Medical Center, 325, Sec. 2, Cheng-Kung Rd., Neihu 114, Taipei, Taiwan \\ ${ }^{4}$ Division of Infectious Diseases, National Health Research Institute, 35, Keyan Rd., Zhunan, Miaoli County, Taipei, \\ Taiwan
}

\begin{abstract}
Klebsiella pneumoniae liver abscess syndrome (KLAS) is an emerging invasive infection caused by highly virulent community-acquired strains of $K$. pneumoniae displaying hypermucoviscosity. The salient features of this syndrome include the presence of bacteremia, primary monomicrobial liver abscess, and metastatic complications. A previously healthy Argentinean man presented with fever and found to have liver abscess caused by K. pneumoniae with metastatic seeding of gastric wall. Cultures from blood and liver abscess grew hypermucoviscous K1 K. pneumoniae with sequence type (ST) 23 by multilocus sequence typing (MLST), positive for rmpA (regulator of mucoid phenotype A), $w z y_{\mathrm{KpK} 1}$ (capsular polymerase) and aerobactin genes. The hypermucoviscous phenotype of this $K$. pneumoniae isolate was readily identified by the "string test" (colonies formed a long string when touched with a loop). The patient responded favourably to percutaneous drainage of the abscess and antibiotics. This is the first documented report of KLAS described in Argentina, and may signal the emergence of this syndrome in South America.
\end{abstract}

Keywords: Liver abscess Hipermucoviscous Klebsiella pneumoniae, RmpA, MagA.

\section{INTRODUCTION}

Highly invasive community-acquired strains of K. pneumoniae with a particular hypermucoviscous phenotype have been reported as a cause of a distinctive syndrome of community-acquired cryptogenic monomicrobial liver abscess with bacteremia, particularly in Taiwan where this disease is endemic [1-10]. Although it is still most frequent in Asia where more than 900 cases have been reported, scattered cases are progressively being reported outside of this region [11]. More than one-half of patients with KLAS have diabetes mellitus, whereas the remainder are otherwise healthy individuals $[5,12,13]$. Septic metastatic complications are frequent $[8,10,14,15]$.

Hypermucoviscous strains of $K$. pneumoniae grow in sticky colonies on agar plates and can be identified by a "string test" Fig. (1) [3, 10, 14].

Most of the isolates from patients with KLAS belong to the $\mathrm{K} 1$ and to lesser extent $\mathrm{K} 2$ serotypes, which are

\footnotetext{
*Address correspondence to this author at the Barrio Dalvian, manzana 36, casa 10. Mendoza, Argentina (5500); Tel: 54261 4444470;

Fax: 54261 4444640; E-mail: santander@arlink.net.ar
}

considered to be the most virulent strains of $K$. pneumoniae $[10,16-20]$. MagA (mucoviscosity-associated gene A) is a chromosomal gene (recently renamed $w z y_{K p K I}$ ) that is required for exopolysaccharide web biosynthesis. This gene, located in the cps (capsular polysaccharide synthesis) operon, is specific of $\mathrm{K} 1$ serotype $[11,12,21]$, thus is a well-accepted target for the detection of K1 serotype [18]. MagA-positive (or serotype K1) K. pneumoniae is accordingly recognized as the main pathogen of pyogenic liver abscess [15].

The plasmid gene rmpA (regulator of mucoid phenotype A) has been shown to be a transcriptional activator of the $w z y_{K P K 1}$ cps loci, thus enhancing extracapsular polysaccharide synthesis in K. pneumoniae [11]. The hypermucoviscous phenotype results from overproduction of extracellular polysaccharides, which is encoded by the chromosome and positively controlled by rmpA gene located on a plasmid [15].

Most isolates of serotype $\mathrm{K} 1 \mathrm{~K}$. pneumoniae from patients with KLAS in Asia belong to ST23.

The following case illustrates the salient features of KLAS and demonstrates the global spread of this infectious disease into South America. 


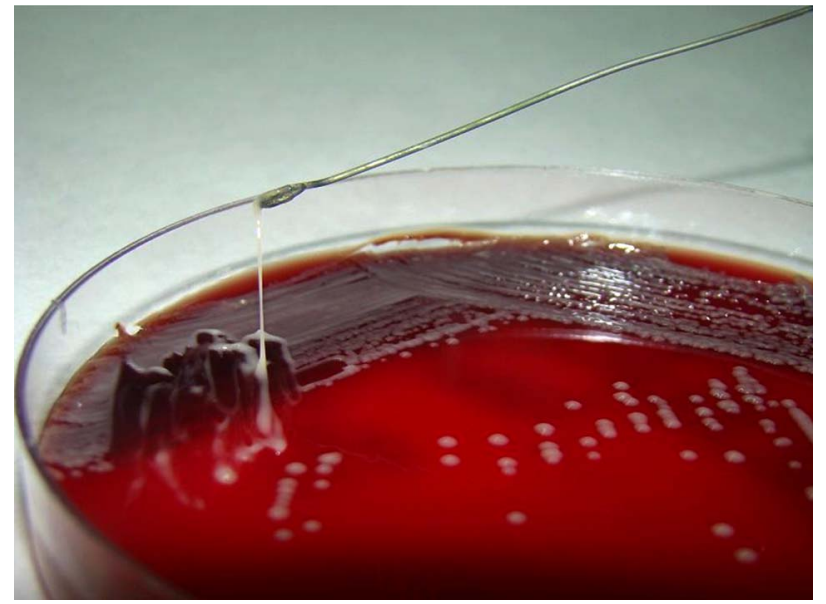

Fig. (1). String test result for Klebsiella pneumoniae. Stretching of $K$. pneumoniae colonies isolated from our patient's sample resulted in the formation of a string $>5 \mathrm{~mm}$ in length, demonstrating the hypermucoviscosity phenotype.

\section{CASE REPORT}

A 55-year-old previously healthy man was admitted with 12 days history of fever and fatigue. He was white, native of Argentina, and denied recent foreign travel, alcohol or drug abuse. He had no significant medical history. He had neither vomiting, nor abdominal spontaneous pain. Clinical examination showed temperature of $40^{\circ} \mathrm{C}$ and tenderness to percussion over the right upper quadrant of the abdomen. The remainder of the physical examination was unremarkable.

Laboratory tests were remarkable for leukocytosis (41 900 cells $/ \mathrm{mm}^{3}$ ), erythrosedimentation rate $73 \mathrm{~mm} /$ hour, $\mathrm{C}$ reactive protein $372 \mathrm{mg} / \mathrm{L}$, and moderate elevation of alkaline phosphatase and g-glutamyl transpeptidase. HIV serology was negative. Fasting plasma glucose levels were normal.

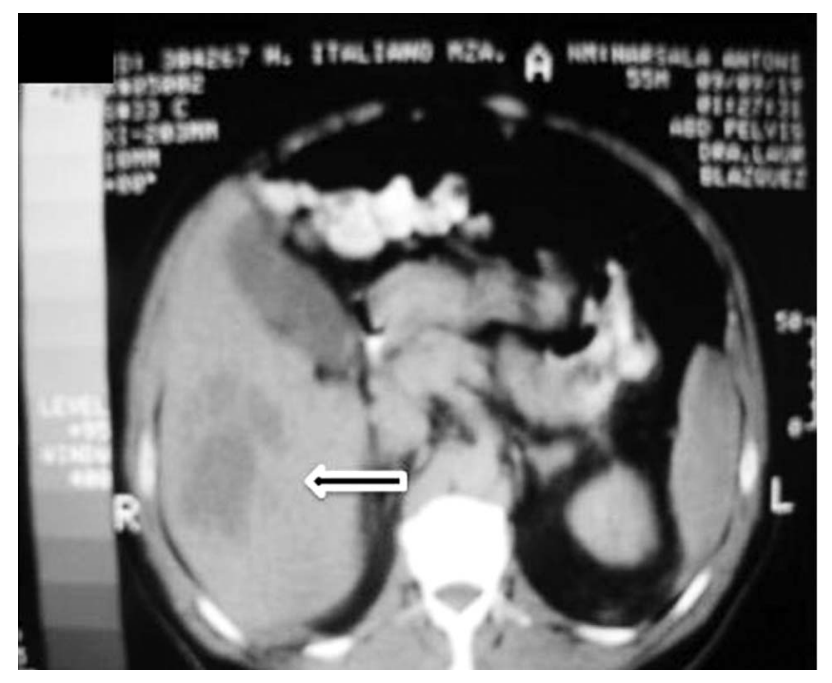

Fig. (2a). Abdominal Computed Tomography (CT) scan images a) CT showing a $15 \mathrm{~cm}$ diameter liver abscess with internal septa and irregular margins.
Abdominal computed tomography (CT) scan with double contrast showed a $15 \mathrm{~cm}$ hypodense lesion with internal septa in the liver Fig. (2a), and a hypodense tumour-like lesion with narrowing of the gastric lumen Fig. (2b). The latter was further investigated by endoscopy-ultrasound (EUS), which showed a 3-cm well-circumscribed hypoechoic submucosal mass suggestive of intramural gastric abscess Fig. (3a,b). Chest x-ray, transthoracic echocardiography and abdominal Doppler ultrasound were normal. Blood cultures were taken.

A presumptive diagnosis of liver abscess was made. The patient was started on ceftriaxone plus metronidazole empirically. Sonography-guided percutanous drainage was placed yielding $60 \mathrm{ml}$ of purulent fluid whose Gram stains showed gram-negative bacilli. Histological examination disclosed inflammatory cells and was negative for malignancy. Blood and abscess aerobic cultures yielded a gram-negative lactose-fermenting bacillus identified as Klebsiella pneumoniae, whose colonies were particularly sticky. Hypermucoviscous phenotype was confirmed by a positive string test: formation of viscous strings $\geq 5 \mathrm{~mm}$ in length when a standard bacteriologic loop was used to stretch the colony on agar plate Fig. (1). Antibiotic susceptibility testing was performed by Etest according to Clinical and Laboratory Standards Institute guidelines. The strains were only intrinsically resistant to ampicillin.

Metronidazole was discontinued. Two weeks after admission the patient became afebrile and drainage was removed. The gastric lesion markedly decreased in size during hospitalization. He was discharged on oral ciprofloxacin to complete a 6-week course. A follow-up CT after antibiotic therapy was completed showed resolution of the abscesses. Patient turned to his usual state of health.

\section{Materials and Methodology}

Four isolates of $K$. pneumoniae from the patient (2 strains from liver abscess and 2 strains from blood) were sent to the

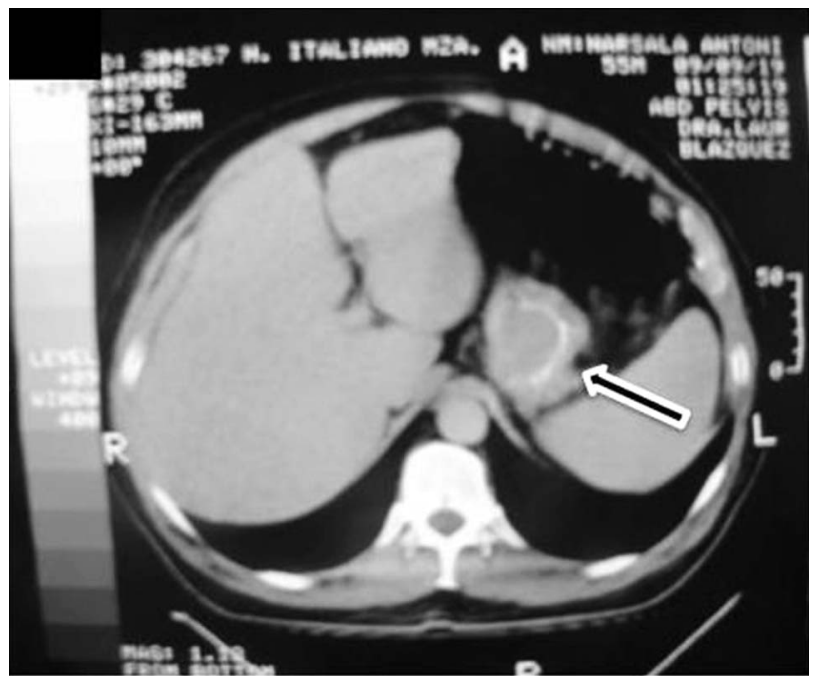

Fig. (2b). CT hypodensity tumour like lesion with narrowing of the gastric lumen (gastric abscess). 


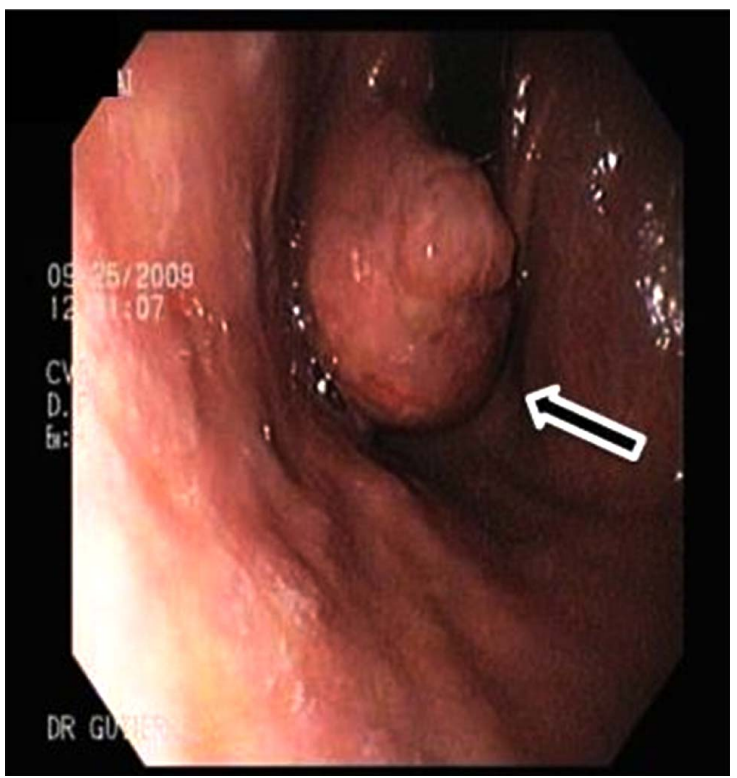

Fig. (3a). Endoscopy showing submucosal mass

National Health Research Institute of Taiwan for further molecular studies.

Isolates were serotyped using capsule swelling reaction with antisera obtained from Health Protection Agency in UK and by PCR as previously described Table $\mathbf{1}$. In addition, one tube multiplex PCR for K1, K2 and K5 were performed according to previously published method [18].

Since $\operatorname{mag} A, \operatorname{rmp} A$ and aerobactin are virulent genes associated with KLAS, PCR was used to target these genes. An overnight-cultured bacterial colony was added to $300 \mu \mathrm{l}$ water and boiled for $15 \mathrm{~min}$ to release DNA template. Previously published primers used for PCR were listed in Table $\mathbf{1 .}$

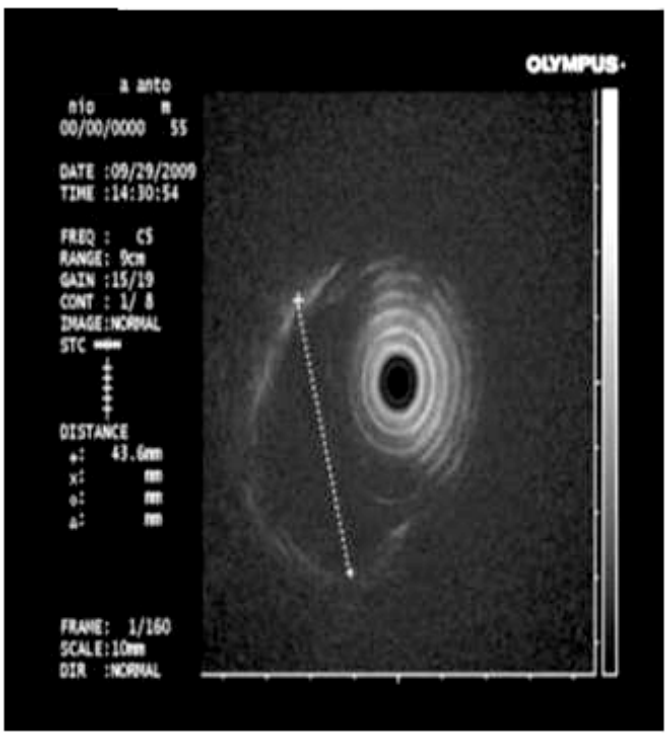

Fig. (3b). Endoscopy-ultrasound demonstrating a 3-cm well circumscribed hypoechoic submucosal mass suggestive of intramural abscess.

The reaction mixture was kept at $95^{\circ} \mathrm{C}$ for $5 \mathrm{~min}$, followed by 40 temperature cycles of $95^{\circ} \mathrm{C}$ for $1 \mathrm{~min}, 50^{\circ} \mathrm{C}$ for $1 \mathrm{~min}$, and $72^{\circ} \mathrm{C}$ for $2 \mathrm{~min}$, and $72^{\circ} \mathrm{C}$ for $7 \min [11,14]$.

MLST was performed according to Turton et al. [9], to characterize the genotype of the isolates, by determining the nucleotide sequences of seven housekeeping genes ( $g a p A$, inf $B$, $m d h$, pgi, phoE, rpoB, and tonB). Sequences of these housekeeping genes were obtained for isolates from liver abscess patients and carriers. Sequences information was compared with those MLST web site (http://pubmlst.org/ kpneumoniae/) developed by Keith Jolley. Alleles and STs were assigned accordingly. Sequences of any alleles that were not on the database were submitted to the curator and

Table 1. Primers Used for Amplification of Target Genes of K. Pneumoniae

\begin{tabular}{|c|c|c|c|}
\hline Target Gene & Primer & Size of PCR Product (bp) & Reference \\
\hline \multicolumn{4}{|l|}{ Serotype } \\
\hline \multirow[t]{2}{*}{ K1 } & 5'-GGTGCTCTTTACATCATTGC-3' & 1283 & {$[18]$} \\
\hline & 5'-GCAATGGCCATTTGCGTTAG-3' & & \\
\hline \multirow[t]{2}{*}{ K2 } & 5'-GACCCGATATTCATACTTGACAGAG-3' & 641 & {$[18]$} \\
\hline & 5'-CCTGAAGTAAAATCGTAAATAGATGGC-3' & & \\
\hline \multirow[t]{2}{*}{ K5 } & 5'-TGGTAGTGATGCTCGCGA-3' & 280 & {$[18]$} \\
\hline & 5'-CCTGAACCCACCCCAATC-3' & & \\
\hline \multirow[t]{2}{*}{ RmpA } & 5'-ACTGGGCTACCTCTGCTTCA-3' & 535 & [47] \\
\hline & 5'-CTTGCATGAGCCATCTTTCA-3' & & \\
\hline \multirow[t]{2}{*}{ Aerobactin } & 5'-GCATAGGCGGATACGAACAT-3' & 556 & {$[47]$} \\
\hline & 5'-CACAGGGCAATTGCTTACCT-3' & & \\
\hline \multirow[t]{2}{*}{ Aerobactin } & 5'-CTGTCGGCATCGGTTTTATT-3' & 531 & {$[47]$} \\
\hline & 5'-TGGCGTGTCGATTATTACCA-3' & & \\
\hline
\end{tabular}


obtained for the allele number. Difference in two or more alleles was considered to be unrelated.

Bacterial DNA was prepared and subjected to PFGE as previously described [9]. The restriction enzyme $X b a \mathrm{I}$ (New England Biolabs, Beverly, MA, USA) was used at the manufacturer's suggested temperature. Restriction fragments were separated by PFGE in 1\% agarose gel (Bio-Rad, Hercules, CA, USA) in $0.5 \times$ TBE buffer $(45 \mathrm{mmol} / \mathrm{L}$ Tris, $45 \mathrm{mmol} / \mathrm{L}$ boric acid, $1.0 \mathrm{mmol} / \mathrm{L}$ EDTA, pH8.0) for $22 \mathrm{~h}$ at $200 \mathrm{~V}$ at a temperature of $14^{\circ} \mathrm{C}$, with ramped times of 2 to $40 \mathrm{~s}$ using the Bio-Rad CHEF MAPPER apparatus (Bio-Rad Laboratories, Richmond, CA, USA). Gels were then stained with ethidium bromide and photographed under ultraviolet light. The resulting genomic DNA profiles, or "fingerprints", were interpreted according to established guidelines [22].

Virulence was determined by mouse inoculation: ten mice were used as a sample population for each bacterial concentration. Since all isolates were identical, one isolate was selected for lethal dose causing $50 \%$ death $\left(\mathrm{LD}_{50}\right)$. A 10 fold serial dilution of CFU of $K$. pneumoniae was made and $\mathrm{BALB} / \mathrm{c}$ mice were injected intraperitonially with $0.1 \mathrm{ml}$ of each concentration. Symptoms and signs of infection were observed for 14 days. Survival of the inoculated mice was recorded and the LD50 was calculated using SigmaPlot version 7.0 from SPSS Inc. (Chicago, IL).

\section{Results}

The results obtained were as follows. All strains from different isolation sites were serotype K1 by PCR and had identical profile by PFGE Fig. (4). All strains were positive for $r m p A, w z y_{\mathrm{KpK} 1}$ and aerobactin genes as revealed by PCR using specific primers Fig. (5), Fig. (6). By using MLST, all

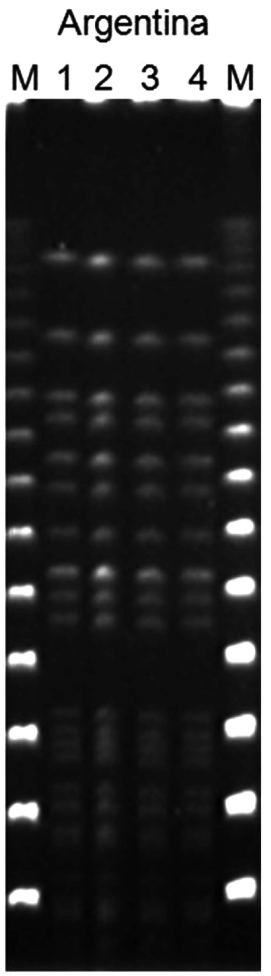

Fig. (4). Pulsed-field gel electrophoresis showing identical profile of all the four isolates ( 2 from blood and 2 from liver abscess) of $K$. pneumoniae from the same patient.

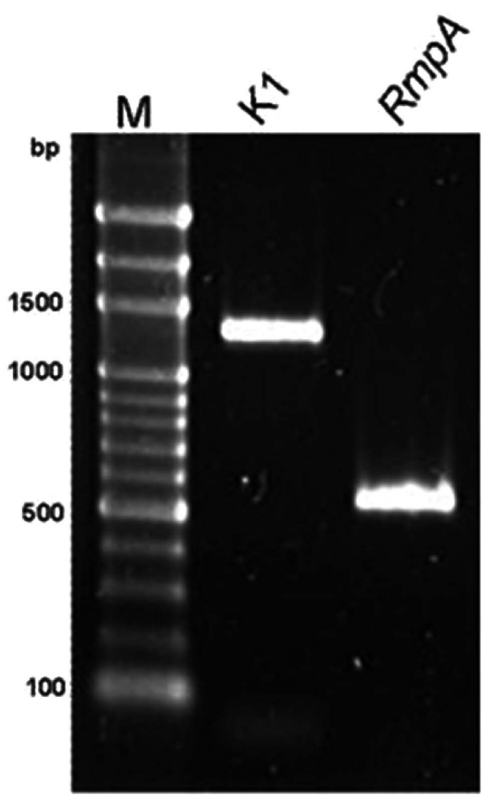

Fig. (5). Polymerase chain reaction detection for $w z y_{K P K l}$ and $r m p A$ genes

\section{Argentina}

aerobactin $531 \quad$ aerobactin 556

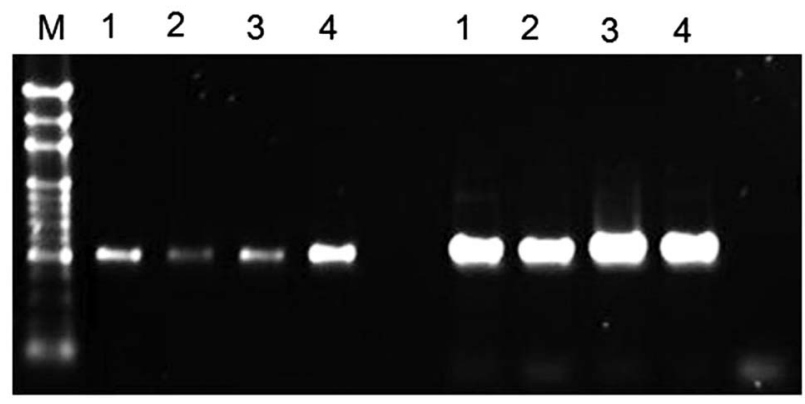

Fig. (6). Positive polymerase chain reaction for aerobactin.

strains belonged to ST 23 (allelic profile: GapA: 2, Inf: 1, Mdh: 1, Pgi: 1, Pho: 9, rpoB: 4, TonB: 12).

The $\mathrm{LD}_{50}$ of the isolate was $<10^{2} \mathrm{CFU}$.

\section{DISCUSSION}

KLAS is a community-acquired tissue invasive infection endemic in Taiwan, where its incidence has increased in the past 20 years [15]. The syndrome seems to be spreading into other geografic areas, as sporadic cases have been reported in North America and Europe [3, 9, 12, 16, 23, 24].

It is remarkable that most of the cases of KLAS outside Asia have involved patients of Asian ethnicity including Filipinos [1, 8, 24-26]; the reasons for this are not known [2, 23]. Our patient was white.

Although half of the cases occur in otherwise healthy people with no underlying hepatobiliary problems, diabetic patients are more susceptible to $K$. pneumoniae infection because poor glycemic control plays an important role in 
phagocytic resistance against $K$. pneumoniae $[1,5,6,8,12$, 26-29].

Patients often complain of vague constitutional symptoms, such as fever and fatigue. Only one-half of patients present with more specific clinical clues as right upper quadrant abdominal pain, jaundice and hepatomegaly $[1,24]$. Our patient only exhibited signs of fever, and had no abdominal complaints. The development of metastatic infection, a rare infectious complication of gram-negative bacteremia affects $10-13 \%$ of patients with KLAS $[1,4,6,8,11,13,30,31]$. Indeed, if defervescence is delayed, a gallium scan is recommended to detect the presence of metastatic infection [1].

Our patient presented a unique septic metastatic complication. Although many distant suppurative lesions have been described, $[15,29]$ abscess of the gastric wall has never been described as a metastatic complication of KLAS Fig. (2), Fig. (3).

Treatment, including pigtail catheter drainage and antimicrobial therapy for 2-8 weeks, is highly effective [1, 24]. Due to the presence of chromosomally mediated SHV-1 Blactamase, which inactivates cefazolin in an inoculumdependent manner, ceftriaxone was prescribed in our patient rather than cefazolin. It has been shown that extendedspectrum cephalosporin, instead of cefazolin optimizes the outcome of KLAS [8].

Multiple virulence characteristics are responsible for the invasiveness of hypermucoviscous $K$. pneumoniae strains. The conspicuous difference between K. pneumoniae and the other enterobacteria is the presence of a thick polysaccharide capsule, which helps the bacterium avoid phagocytosis, being its principal virulence factor $[10,11,21,32]$. According to the capsular polysaccharide, K. pneumoniae can be classified into 77 serological $\mathrm{K}$ antigen types, distributed across different geographical areas. $\mathrm{K} 1$ is the predominant serotype that causes KLAS in Asia [5, 6, 33-35].

Hypermucoviscous phenotypes are encapsulated strains of $K$. pneumoniae (mostly K1 and to a lesser extent K2) that produce vasts amounts of extracapsular polysaccharide constituting a mucoviscous web that protects these strains from phagocytosis by neutrophils and from serum killing by complement $[24,30,36]$. Hypermucoviscous isolates demonstrate increased virulence in mice $[4,10]$, and grow in sticky colonies that form long $(>5 \mathrm{~mm})$ mucous strings when touched with a bacteriological loop (string test) $[9,10,37$, 38] (Fig. (1)). This test provides an easy, rapid diagnostic tool and was prominently seen for the $K$ pneumoniae isolated from our patient $[8,39]$.

The biochemical nature of the mucoid phenotype may be unrelated to capsular polysaccharide but rather related to extracapsular polysaccharide [10]. A number of chromosomal and plasmid genes have been proposed or suggested to play key roles generation of the hypermucoviscous phenotype [23]. Chromosomal magA gene, which encodes a structural outer membrane protein essential for the production of the exopolysaccharide web, is associated with hypermucoviscous phenotype [14]. Further sequencing of $\mathrm{mag} A$ flanking region revealed that $\operatorname{mag} A$ was the serotype $\mathrm{K} 1$ allele of the polymerase wzy loci in the cps operon (i.e., serotype K1 polymerase gene) [6, 11, 12, 16, 32, 40, 41].
Although the wzy gene has been proposed to encode an Opolysaccharide polymerase that recognizes and extends the O-antigen polysaccharide-repeating units in the capsular synthesis process [42], recent investigations have shown it is responsible for $\mathrm{K}-$ but not $\mathrm{O}$-antigen polymerization [12]. The cps gene clusters of serotypes K1, K2, K5, K20, K54, and K57 have different alleles at both wzy and wzx loci [6]. With the confirmation that $\operatorname{mag} A$ was a K1-antigen-specific polymerase, and in accordance with the bacterial polysaccharide gene nomenclature scheme, it has been proposed that $m a g A$ has to be renamed $w z y_{K p K l}$, the capsular polymerase specific to K. pneumoniae serotype K1 [12]. So $w z y_{K p K 1}$ is a chromosomal gene located in the cps gene cluster for serotype K1 capsular formation, therefore it is restricted to and present in all of the isolates of this serotype, regardless of virulence $[11,12,43,44]$. Although the deletion mutant of the wzy gene decreases mucoviscosity [42], this gene should be considered a component of K1 capsule formation rather than an independent specific virulence gene for K. pneumoniae strains causing liver abscess $[16,44]$.

Two plasmid encoded virulence genes, rmpA and aerobactin, are significant correlated with the high virulence of the invasive strains $[17,36,45,46]$. RmpA gene was first described by Nassif et al. in 1989 [47]. Yu et al. demonstrated that $r m p A$-carrying strains were associated with the hypermucoviscous phenotype, as well as with the invasive clinical syndrome [26, 32, 48]. RmpA gene is a transcriptional activator of the cps genes and functions as a positive regulator of extracapsular polysaccharide synthesis [49]. Mostover, mutation in rmpA lowers in $13 \%-29 \%$ capsule production [11].

Overproduction of extracellular polysaccharide is encoded by the chromosome and positively controlled by rmpA located on a plasmid.

The growth of bacteria in host tissues is limited not only by host defense mechanisms but also by its supply of available iron. Many bacteria attempt to secure their supply of iron in the host by secreting high affinity iron chelators called siderophores, like aerobactin. Aerobactin can increase virulence in mouse lethality tests by 100 -fold $[46,50]$. The aerobactin and rmp $A$ genes have been identified to be simultaneously located on a 180 -kilobase plasmid $[10,17]$, thus, the presence of rmpA gene and phenotypic evidence of aerobactin production are closely correlated [10].

The K. pneumoniae isolate of our patient was a K1 serotype with hypermucoviscous phenotype carrying $\operatorname{rmp} A$, aerobactin and $w z y_{K p K l}$ genes. It is noteworthy that $\mathrm{K} 1$ serotype is infrequent in clinical isolates from Western countries [33].

Although $\mathrm{K}$ serotyping has been the dominant common language for recognition of related $K$. pneumoniae strains in epidemiological and virulence studies, demonstration of clonal dissemination requires genotypic studies. Comparison of isolates by PFGE has several limitations, including different definitions of clonality from different laboratories. MLST is a nucleotide sequence-based typing method that successfully catalogs bacterial pathogens, with complete reproducibility among laboratories, overcoming the limitations of band-based typing methods $[34,51]$. Isolates with 
the same K type may belong to unrelated STs. Indeed, most K-types belong to unrelated STs, and the shared K type results from horizontal transfer of the cps operon among unrelated genotypes. Therefore, knowledge of the $\mathrm{K}$ type provides unreliable prediction of clone identity [21].

It has been shown that $\mathrm{K} 1$ serotype $K$. pneumoniae strains responsible for endemic KLAS in Asia, are genetically homogeneous, and belong to ST23 [34], which have been shown to be more virulent in animal lethality studies than other STs. (L. K. Siu, personal communication). Our isolation belonged to ST23, suggesting its global dissemination.

All ST23 clinical strains reported are susceptible to antibiotics commonly used for Klebsiella infections [51]. This pattern of susceptibility has remained unchanged. Virulence and resistance are not independent properties; furthermore, genes and environment interact to determine the fitness costs of resistance. The relationship between virulence and resistance may play an important role in the pathogenesis of this invasive infection. It is plausible that the acquisition of resistance may affect the virulence of the bacteria $[1,14]$.

This represents the first reported case of hypermucoviscous serotype K1 K. pneumoniae associated with liver abscess and bacteremia in Argentina. These strains can be readily detected by the string test (Fig. (1)). MLST and molecular characterization of hypermucoviscous phenotype associated genes is straightforward. Further geographic dissemination of hypermucoviscous K1 K. pneumoniae strains of ST23 is likely. Increased awareness about KLAS by physicians and public health officials in South America and worldwide could allow earlier detection and optimal treatment of patients [26]. A rising number of cases from other geographic regions indicate that this is a globally emerging infectious disease.

\section{ACKNOWLEDGMENTS}

We would like to thank María Belén Martín, Miguel Angel Distefano, Enrique Ahumada, and Juan Luis Manzur for assistance with international exportation procedures.

We are extremely grateful to Victor $\mathrm{Yu}$, for his invaluable advice and for critical reading the manuscript.

We also like to thank Patricio Briggs and Jorge Isaguirre for providing images.

This study was supported by a grant from the National Science Council. Grant number: (NSC-99-2320-B-400-005MY3).

Potential conflicts of interest: all authors: no conflicts.

\section{REFERENCES}

[1] Wang JH, Liu YC, Lee SS, et al. Primary liver abscess due to Klebsiella pneumoniae in Taiwan. Clin Infect Dis 1998; 26: 14348.

[2] Ko WC, Paterson DL, Sagnimeni AJ, et al. Community-acquired Klebsiella pneumoniae bacteremia: global differences in clinical patterns. Emerg Infect Dis 2002; 8: 160-6.

[3] Fang FC, Sandler N, Libby SJ. Liver abscess caused by $\operatorname{mag} A+$ Klebsiella pneumoniae in North America. J Clin Microbiol 2005; 43: 991-2.

[4] McCabe R, Lambert L, Frazee B. Invasive Klebsiella pneumoniae Infections, California, USA. Emerg Infect Dis 2010; 16: 1490-1.
[5] Cheng KS, Tang HL, Hsu CH, Lai HC, Yu CJ, Chou FT. A clinical survey of Klebsiella pneumoniae virulence and genotype in pyogenic liver abscess. Adv Ther 2007; 24: 589-93.

[6] Fang CT, Lai SY, Yi WC, Hsueh PR, Liu KL, Chang SC. Klebsiella pneumoniae genotype $\mathrm{K} 1$ : an emerging pathogen that causes septic ocular or central nervous system complications from pyogenic liver abscess. Clin Infect Dis 2007; 45: 284-93.

[7] Liu YC, Cheng DL, Lin CL. Klebsiella pneumoniae liver abscess associated with septic endophthalmitis. Arch Intern Med 1986; 146: 1913-6

[8] Keynan Y, Rubinstein E. Endogenous endophthalmitis caused by hypermucoviscous Klebsiella pneumoniae: an emerging disease in Southeast Asia and beyond. Curr Infect Dis Rep 2008; 10: 343-5.

[9] Turton JF, Englender H, Gabriel SN, Turton SE, Kaufmann ME, Pitt TL. Genetically similar isolates of Klebsiella pneumoniae serotype $\mathrm{K} 1$ causing liver abscesses in three continents. J Med Microbiol 2007; 56: 593-7.

[10] Yu VL, Hansen DS, Ko WC, et al. Virulence characteristics of Klebsiella and clinical manifestations of $K$. pneumoniae bloodstream infections. Emerg Infect Dis 2007; 13: 986-93.

[11] Chuang YP, Fang CT, Lai SY, Chang SC, Wang JT. Genetic determinants of capsular serotype $\mathrm{K} 1$ of Klebsiella pneumoniae causing primary pyogenic liver abscess. J Infect Dis 2006; 193: 645-54.

[12] Yeh KM, Lin JC, Yin FY, et al. Revisiting the importance of virulence determinant magA and its surrounding genes in Klebsiella pneumoniae causing pyogenic liver abscesses: exact role in serotype K1 capsule formation. J Infect Dis 2010; 201: 1259-67.

[13] Chou HC, Lee CZ, Ma LC, Fang CT, Chang SC, Wang JT. Isolation of a chromosomal region of Klebsiella pneumoniae associated with allantoin metabolism and liver infection. Infect Immun 2004; 72: 3783-92.

[14] Fang CT. A novel virulence gene in Klebsiella pneumoniae strains causing primary liver abscess and septic metastatic complications. J Exp Med 2004; 199: 697-705.

[15] Tsai F-C. Pyogenic liver abscess as endemic disease, Taiwan. Emerging Infect Dis 2008; 14: 1592-600.

[16] Struve C. Investigation of the putative virulence gene $\operatorname{mag} A$ in a worldwide collection of 495 Klebsiella isolates: $m a g A$ is restricted to the gene cluster of Klebsiella pneumoniae capsule serotype K1. J Med Microbiol 2005; 54: 1111-3.

[17] Hsieh PF, Lin TL, Lee CZ, Tsai SF, Wang JT. Serum-induced ironacquisition systems and TonB contribute to virulence in Klebsiella pneumoniae causing primary pyogenic liver abscess. J Infect Dis 2008; 197: 1717-27.

[18] Turton JF, Baklan H, Siu LK, Kaufmann ME, Pitt TL. Evaluation of a multiplex PCR for detection of serotypes $\mathrm{K} 1, \mathrm{~K} 2$ and $\mathrm{K} 5$ in Klebsiella $s p$. and comparison of isolates within these serotypes. FEMS Microbiol Lett 2008; 284: 247-52.

[19] Yang YS, Siu LK, Yeh KM, et al. Recurrent Klebsiella pneumoniae liver abscess: clinical and microbiological characteristics. J Clin Microbiol 2009; 47: 3336-9.

[20] Yu WL, Chan KS, Ko WC, Lee CC, Chuang YC. Lower prevalence of diabetes mellitus in patients with Klebsiella pneumoniae primary liver abscess caused by isolates of $\mathrm{K} 1 / \mathrm{K} 2$ than with non-K1/K2 capsular serotypes. Clin Infect Dis 2007; 45 : 1529-30; author reply 32-3.

[21] Brisse S, Fevre C, Passet V, et al. Virulent clones of Klebsiella pneumoniae: identification and evolutionary scenario based on genomic and phenotypic characterization. PLoS One 2009; 4: e4982.

[22] Tenover FC, Arbeit RD, Goering RV, et al. Interpreting chromosomal DNA restriction patterns produced by pulsed-field gel electrophoresis: criteria for bacterial strain typing. J Clin Microbiol 1995; 33: 2233-9.

[23] Keynan Y, Rubinstein E. The changing face of Klebsiella pneumoniae infections in the community. Int J Antimicrob Agents 2007; 30: 385-9.

[24] Casella F, Finazzi L, Repetti V, et al. Liver abscess caused by Klebsiella pneumoniae: two case reports. Cases J 2009; 2: 6879.

[25] Rahimian J, Wilson T, Oram V, Holzman RS. Pyogenic liver abscess: recent trends in etiology and mortality. Clin Infect Dis 2004; 39: 1654-9.

[26] Nadasy KA, Domiati-Saad R, Tribble MA. Invasive Klebsiella pneumoniae Syndrome in North America. Clin Infect Dis 2007; 45: e25-e28. 
[27] Cheng HP, Chang FY, Fung CP, Siu LK. Klebsiella pneumoniae liver abscess in Taiwan is not caused by a clonal spread strain. J Microbiol Immunol Infect 2002; 35: 85-8.

[28] Lin JC. Impaired phagocytosis of capsular serotypes K1 or K2 Klebsiella pneumoniae in type 2 diabetes mellitus patients with poor glycemic control. J Clin Endocrinol Metab 2006; 91: 3084-7.

[29] Dylewski JS, Dylewski I. Necrotizing fasciitis with Klebsiella liver abscess. Clin Infect Dis 1998; 27: 1561-2.

[30] Cerwenka H. Pyogenic liver abscess: differences in etiology and treatment in Southeast Asia and Central Europe. World J Gastroenterol 2010; 16: 2458-62.

[31] Lederman ER, Crum NF. Klebsiella liver abscess: a coast-to-coast phenomenon. Clin Infect Dis 2005; 41: 273.

[32] Wu KM, Li LH, Yan JJ, Tsao N, Liao TL, Tsai HC, et al. Genome sequencing and comparative analysis of Klebsiella pneumoniae NTUH-K2044, a strain causing liver abscess and meningitis. J Bacteriol 2009; 191: 4492-501.

[33] Kim JK, Chung DR, Wie SH, Yoo JH, Park SW. Risk factor analysis of invasive liver abscess caused by the K1 serotype Klebsiella pneumoniae. Eur J Clin Microbiol Infect Dis 2009; 28 : 109-11.

[34] Chung DR, Lee HR, Lee SS, et al. Evidence for clonal dissemination of the serotype K1 Klebsiella pneumoniae strain causing invasive liver abscesses in Korea. J Clin Microbiol 2008; 46: 4061-3.

[35] Kim JK, Chung DR, Wie SH, Yoo JH, Park SW. Risk factor analysis of invasive liver abscess caused by the K1 serotype Klebsiella pneumoniae. Eur J Clin Microbiol Infect Dis 2008; 28: 109-11.

[36] Rivero A, Gomez E, Alland D, Huang DB, Chiang T. K2 serotype Klebsiella pneumoniae causing a liver abscess associated with infective endocarditis. J Clin Microbiol 2010; 48: 639-41.

[37] McIver C, Janda J. Pathogenesis and laboratory identification of emerging hepatovirulent Klebsiella pneumoniae. Clin Microbiol Newsletter 2008; 30: 127-31.

[38] Kawai T. Hypermucoviscosity: an extremely sticky phenotype of Klebsiella pneumoniae associated with emerging destructive tissue abscess syndrome. Clin Infect Dis 2006; 42: 1359-61.

[39] Cheng HP, Siu LK, Chang FY. Extended-spectrum cephalosporin compared to cefazolin for treatment of Klebsiella pneumoniaecaused liver abscess. Antimicrob Agents Chemother 2003; 47: 2088-92.

[40] Fang CT, Lai SY, Yi WC, Hsueh PR, Liu KL. The function of $w z y \_\mathrm{K} 1(\operatorname{mag} A)$, the serotype $\mathrm{K} 1$ polymerase gene in Klebsiella pneumoniae cps gene cluster. J Infect Dis 2010; 201: 1268-9.
[41] Yeh KM, Kurup A, Siu LK, et al. Capsular serotype K1 or K2, rather than $\operatorname{mag} A$ and $\operatorname{rmp} A$, is a major virulence determinant for Klebsiella pneumoniae liver abscess in singapore and taiwan. J Clin Microbiol 2006; 45: 466-71.

[42] Pan YJ, Fang HC, Yang HC, et al. Capsular polysaccharide synthesis regions in Klebsiella pneumoniae serotype K57 and a new capsular serotype. J Clin Microbiol 2008; 46: 2231-40.

[43] Burke RL, Whitehouse CA, Taylor JK, Selby EB. Epidemiology of invasive Klebsiella pneumoniae with hypermucoviscosity phenotype in a research colony of nonhuman primates. Comp Med 2009; 59: 589-97.

[44] Yeh KM, Chang FY, Fung CP, Lin JC, Siu LK. MagA is not a specific virulence gene for Klebsiella pneumoniae strains causing liver abscess but is part of the capsular polysaccharide gene cluster of $K$. pneumoniae serotype K1. J Med Microbiol 2006; 55: 803-4.

[45] Sobirk SK, Struve C, Jacobsson SG. Primary Klebsiella pneumoniae liver abscess with metastatic spread to lung and eye, a northeuropean case report of an emerging syndrome. Open Microbiol J 2010; 4: 5-7.

[46] Yu WL, Ko WC, Cheng KC, Lee CC, Lai CC, Chuang YC. Comparison of prevalence of virulence factors for Klebsiella pneumoniae liver abscesses between isolates with capsular K1/K2 and non-K1/K2 serotypes. Diagn Microbiol Infect Dis 2008; 62: $1-6$.

[47] Nassif X, Honore N, Vasselon T, Cole ST, Sansonetti PJ. Positive control of colanic acid synthesis in Escherichia coli by rmpA and rmpB, two virulence-plasmid genes of Klebsiella pneumoniae. Mol Microbiol 1989; 3: 1349-59.

[48] $\mathrm{Yu}$ WL, Ko WC, Cheng KC, et al. Association between rmpA and $m a g A$ genes and clinical syndromes caused by Klebsiella pneumoniae in Taiwan. Clin Infect Dis 2006; 42: 1351-8.

[49] Wacharotayankun R, Arakawa Y, Ohta M, et al. Enhancement of extracapsular polysaccharide synthesis in Klebsiella pneumoniae by RmpA2, which shows homology to NtrC and FixJ. Infect Immun 1993; 61: 3164-74.

[50] Nassif X, Sansonetti PJ. Correlation of the virulence of Klebsiella pneumoniae $\mathrm{K} 1$ and $\mathrm{K} 2$ with the presence of a plasmid encoding aerobactin. Infect Immun 1986; 54: 603-8.

[51] Ko KS, Lee JY, Baek JY, et al. Predominance of an ST11 extended-spectrum -lactamase-producing Klebsiella pneumoniae clone causing bacteraemia and urinary tract infections in Korea. J Med Microbiol 2010; 59: 822-8. 